\title{
The Correlation between Selenium-Dependent Glutathione Peroxidase Activity and Oxidant/Antioxidant Balance in Sera of Diabetic Patients with Nephropathy
}

\author{
Abdulateef Altuhafi ${ }^{1,2,4}$, Muhammed Altun ${ }^{3}$, Mahmoud Hussein Hadwan*2
}

\begin{abstract}
Background: Oxidative stress is an imbalance between free radical's production and the body's ability to counteract or detoxify their harmful effects through neutralization by antioxidants, oxidative stress is thought to be involved in the pathogenesis of diabetic nephropathy. One of the key enzymatic antioxidants is glutathione peroxidase (GPx), which plays an important protective function in diabetes complications, by reducing the rising state of oxidative stress and removing toxicity from peroxides and converting them into a non-toxic substance. The objective of this research was to evaluate the rule of glutathione peroxidase in regulate oxidants/antioxidants levels diabetic patients with nephropathy.

Methods: In a case-control study, we assessed serum GPx activity (Se-Dependent, non-selenium dependent and total GPx), total oxidant, lipid peroxidation, total antioxidant, and catalase in healthy control subjects (group 1), in diabetic patients without diabetic nephropathy (group 2) and diabetic patients with nephropathy (group 3).

Results: GPx activity was significantly lower in T2D patients with and without nephropathy compared to healthy subject's control. Total oxidants and lipids peroxidation have a negative correlation with the GPx and other antioxidants.

Conclusions: Decreased GPx activity indicate a relationship between GPx activity and diabetic nephropathy.
\end{abstract}

Keywords: Diabetic Nephropathy, Glutathione Peroxidase, Oxidative Stress, Reactive Oxygen Species, Selenium.

\section{Introduction}

Diabetes mellitus (DM) is a chronic disease with increasing prevalence worldwide, result from a metabolism disorder, described as high blood sugar, as a result of either dysfunction of insulin or insulin deficiency. In the long term, high blood sugar may be associated with the development of many diseases that cause impairment or failure in various parts of the body, like damage to the eyes, nerves, kidneys and heart. Moreover, hyperglycemia causes oxidative stress, that raises the possibility of complications (1). Diabetes contributes to stimulating pathological changes in the large blood vessels and microvasculature that leads to complications of diabetes. Retinopathy, nephropathy and neuropathy are the result of complications of microvascularity in the case of diabetes. Diabetic nephropathy it is the most 
feared outcome for diabetes. It is a chronic disease that occurs in the kidney, and its most important feature that associates with the occurrence of albuminuria continuously, in addition to the gradual and continuous decrease in the glomerular filtration rate (2). Diabetes develops into diabetic nephropathy by $20 \%$ to $30 \%$ of all cases (3). Previous studies indicate a relationship between the development of metabolic diseases and the presence of oxidative stress. The linkage between oxidative stress and chronic inflammation may acts as a precursor to these diseases (4). Oxidative stress can be expressed by the presence of an imbalance between the levels of antioxidants and oxidants that lead to tissue damage. The production of reactive oxygen species in the mitochondria can cause damage of the mitochondria itself In the event that ROS are left uncontrolled by the defensive systems, they can cause oxidative damage to (DNA), membrane lipids and proteins (5). Previous studies indicate that a chronic rise in glucose concentration acts to generate reactive oxygen species, which in turn leads to an increase oxidative damage of beta cells. Finally, ROS cause the inability of beta cells to work normally in terms of insulin secretion (6). Glomerular mesangial cells are unable to manage the excessive rise in sugar and are unable to regulate it. As a result, glomerular mesangial cells particularly have been exposing to attack the blood sugar, and thus increase the productivity of superoxide and other types of reactive oxygen species (7).

The defensive system contains specific enzymes for example superoxide dismutase (SOD), glutathione peroxidase (GPx) and Catalase (CAT) that are produced inside the tissues during various metabolism processes. These enzymes interact with free radicals and can safely end their path (8). Glutathione peroxidase is considered as one of the very important antioxidants in the defense system against the rise in oxidative stress (OS). The role of GPx was shown by its change activity in many diseases, including diabetes, kidney disease and heart disease (5). Glutathione peroxidase in its composition contains a selenium, that is located in the active site of the enzyme and plays a major and important role in the defensive function against oxidative stress (9). After $\mathrm{H}_{2} \mathrm{O}_{2}$ production by SOD, the GPx enzyme act to remove the toxicity of excess hydrogen peroxide and reduced it into $\mathrm{H}_{2} \mathrm{O}$, using glutathione (GSH) and oxidizing it to glutathione disulfide (GSSG) (10). The importance of this enzyme lies in its high efficiency and ability to perform more than one function, as in addition to the detoxification of hydrogen peroxide also can reduced hydroperoxides into alcohol in the same reaction (11).

\section{Materials and Methods}

All blood samples of patients were collected in fasting state (9-11 A.m.) in $\mathrm{Al}$ Hashemite General Hospital (Babylon, Iraq). The clinical study was performed between (February 2020 to October 2020).

\section{Study design}

The current study included 180 male subjects (60 Diabetic patients without nephropathy and 60 Diabetic patients with nephropathy) and 60 healthy male subjects. The participants were classified to:

G1: healthy subjects' group.

G2: diabetic patients without nephropathy group.

G3: diabetic patients with nephropathy group.

\section{Inclusion and Exclusion Criteria}

The medical history of each participant in the study was taken, which includes family history, period of the disease, types of treatments used, in addition to a mention in a case diagnosed with another disease affecting the study. To calculate the body mass index of the study participants, weight and height were measured. The current study focused on patients with and without nephropathy with more than one year. Controls subjects were selected from healthy adult volunteers with established levels of FBS $<100$ $\mathrm{mg} / \mathrm{dl}$. Informed written consent was taken from each participant. Initially, all subjects were interviewed for their medical history and were examined. Both in cases and controls, exclusion criteria were set as having: T1DM patients, 
females, cigarette smokers, have a history of heart failure, obese patients, a history of hyperthyroidism, history of hypothyroidism, a malignancy account, disease of the liver patients, and use of insulin, antioxidants, and lipidlowering drugs.

\section{Chemicals}

All chemicals were used as supplied without any purification.

\section{Microalbuminuria Assay}

For assess microalbuminuria concentration in urine the (Combina 13 Strips kit) was utilized. It is based on the response of the suitable indicator, which is arisen from the presence of albumin. Microalbuminuria was assayed by immersing the strip in the urine approximately two seconds and let stand for one minute then compare the reagent areas on the strip with the corresponding charts of colour fields on the container.

\section{Assessment of Glycosylated Hemoglobin (HbA1C)}

The blood glycosylated hemoglobin is estimated by performing HbA1c test (Stanbio Systems is a USA HbA1c assessment Kit). (12) (13).

\section{Glutathione Peroxidase Activity Assays}

The method selected Rotruck et al. (14) Where 50 microlitres $(50 \mu \mathrm{l})$ of DTNB at $0.04 \%$ and $100 \mu \mathrm{l}$ of $\mathrm{K}_{2} \mathrm{HPO}_{4}$ at $0.3 \mathrm{M}$ added to $50 \mu \mathrm{l}$ volume of solutions standards $(25,50,100$, $150,200 \mu \mathrm{M})$ of EDTA. Reduced glutathione in this method plays as standard. At $412 \mathrm{~nm}$, the reaction mixture absorbance was read against the blank and the concentrations were plotted against the absorbance. From curve standard generated, the reduced glutathione levels were estimated. For GPx activity assessment, the mixture of reaction was prepared from $100 \mu \mathrm{l}$ of $\mathrm{NaN} 3,500 \mu \mathrm{l}$ from potassium phosphate buffer at ( $\mathrm{pH} 7.5), 500 \mu \mathrm{l}$ $\mathrm{H}_{2} \mathrm{O}, 200 \mu \mathrm{l}$ of glutathione, $100 \mu \mathrm{l} \mathrm{H}_{2} \mathrm{O}_{2}, 600$ $\mu 1$ from the sample. The mixture was incubated before centrifugation (for five minutes at $3000 \mathrm{rpm}$ ), at $37^{\circ} \mathrm{C}$, for 3 minutes and $0.5 \mathrm{ml}$ of $10 \%$ TCA was added. To $50 \mu \mathrm{l}$ of the supernatant or standards, $50 \mu 1$ of $0.04 \%$ DTNB and $100 \mu \mathrm{l}$ of $0.3 \mathrm{M} \mathrm{K}_{2} \mathrm{HPO}_{4}$ was added. Against the blank and at $(412 \mathrm{~nm})$ the reaction mixture absorbance was read. From the standard curve, the remaining glutathione concentration was estimated.

245.34 - Glutathione remaining=Glutathione consumed Amount of Glutathione consumed / $\mathrm{mg}$ of protein $=$ GPX activity.

Non-Se-dependent glutathione peroxidase activity determined by using cumene hydroperoxide as a substrate rather than hydrogen peroxide. By applying the following equation, Total glutathione peroxidase activity was obtained.

Total glutathione peroxidase activity $=[$ NonSe-dependent glutathione peroxidase activity] + [Se-dependent glutathione peroxidase activity].

\section{Catalase Activity Assay}

Catalase activity was estimated using the Hadwan method (15). A mixture of $(1000 \mu \mathrm{l}$ of hydrogen peroxide and $100 \mu \mathrm{l}$ of sample) was vortexed and incubated for three minutes. Then, $2 \mathrm{~mL}$ of dichromate/acetic acid were added to each test. In place of hydrogen peroxide, distilled water was added to control and standard tests. After the previous additions and before the centrifugation process $(2500 \mathrm{~g}$ for five minutes after cooling to remove precipitated protein), the tubes were kept for ten minutes at $100{ }^{\circ} \mathrm{C}$. Against the blank, the absorbance was read at $570 \mathrm{~nm}$. Catalase activity was calculated by the equation:

$2.303 / \mathrm{t} \times\left[\log \mathrm{S}^{0} / \mathrm{S}-\mathrm{M}\right] \times \mathrm{Vt} / \mathrm{Vs}$ where: $\mathrm{t}$; Time needed for the reaction to happen, $S$; Standard tube absorbance, S; Test tube absorbance, M; Control test absorbance, Vt: The reagents total volume in the test tube and Vs: Volume of serum

\section{Total Antioxidants Capacity Assay}

For total antioxidant capacity measurement, the CUPRAC method was utilized (16). The reaction mixture was prepared by adding ammonium acetate (NH4Ac) buffer ( $\mathrm{pH} 7.0)$ to copper (II) chloride solution (10-2M) and Neocuproine $\quad$ (Nc) $\{2,9$-dimethyl-1,10- 
phenanthroline $\}$ solution $(7.5 * 10-3 \mathrm{M}) .1 \mathrm{ml}$ $(1000 \mu \mathrm{l})$ of the reaction mixture was added to the test tubes and $50 \mu \mathrm{l}$ of Trolox at $1.0 * 10$ $3 \mathrm{M}$ (standard) was added to the standard tube, while $50 \mu \mathrm{l}$ of water was added to the blank tube. In addition, $50 \mu 1$ of the sample is added to the sample tube. Test tubes were mixed by vortex and incubated for 30 minutes at $37{ }^{\circ} \mathrm{C}$, after that the absorbance was read on a spectrophotometer at $450 \mathrm{~nm}$ and using the equation:

Total antioxidants levels $=\frac{\text { A. test }}{\text { A. STD }} *$ Con. of STD $(\mu \mathrm{mol} / 1)$

\section{Total Oxidant Status (TOS)}

Serum total oxidant status was determined by utilizing a method based on oxidizing the ferrous ion-o-dianisidine complex to yield the ferric ion-o-dianisidine (17). This method contains two types of reagents, the first reagent was prepared by dissolving $3.17 \mathrm{~g}$ of $\mathrm{O}-$ dianisidine dihydrochloride and $1.96 \mathrm{~g}$ of ferrous ammonium sulfate in $1000 \mathrm{~mL}$ of $\mathrm{H} 2 \mathrm{SO} 4$ solution, $25 \mathrm{mM}$. The ending reagent was composed of $10 \mathrm{mM}$ O-dianisidine dihydrochloride and $5 \mathrm{mM}$ ferrous ammonium sulfate. The second reagent was prepared by dissolving $8.18 \mathrm{~g}$ of $\mathrm{NaCl}$ and $114 \mathrm{mg}$ of xylenol orange in $900 \mathrm{~mL}$ of $25 \mathrm{mM} \mathrm{H} 2 \mathrm{SO} 4$ solution. The solution was completed to $1 \mathrm{~L}$ by adding one hundred milliliters of glycerol. The final concentrations of components in the reagent are $150 \mu \mathrm{M}$ xylenol orange, $140 \mathrm{mM}$ $\mathrm{NaCl}$ and $1.35 \mathrm{M}$ glycerol. The $\mathrm{pH}$ value was (1.75) for the equilibrium reagent. $1 \mathrm{ml} \mathrm{(1000}$ $\mu \mathrm{l})$ of the first mixture were added to the test tubes and distilled water $(25 \mu \mathrm{l})$ were added to the blank tube. $25 \mu \mathrm{l}$ of hydrogen peroxide (Standard) were added to the standard tube and serum sample $(25 \mu \mathrm{l})$ were added to sample tube. Test tubes were mixed by vortex, and then the second reagent $(250 \mu \mathrm{l})$ was added. The content of each tube was quietly mixed after addition, standing at room temperature for 3 minutes was allowed, spectrophotometrically at $560 \mathrm{~nm}$ was read and using the equation:

Total Oxidants Status $\mu \mathrm{mol} / \mathrm{l}=\frac{\text { Asample }}{\text { Astanderd }} \times$ Standard conc.

\section{Lipid Peroxidation Assay}

The thiobarbituric acid reactive substances (TBARS) assay was used to estimate lipid peroxides in the study subjects (18). In micro tubes, $100 \mu$ of MDA (Standard) solution (2, $4,6,8,10 \mu \mathrm{M}$ ) were added to $0.04 \%$ butylated hydroxytoluene (BHT), $1 \mathrm{ml}$ of $0.67 \%(\mathrm{w} / \mathrm{v})$ TBA, $1 \mathrm{ml}$ of $20 \%(\mathrm{w} / \mathrm{v})$ trichloroacetic acid (TCA). For 20 minutes, the mixture was incubated in boiling water and left at room temperature (cooling). Then, for 10 minutes at $4000 \mathrm{~g}$, the tubes were centrifuged, and the absorbance was read at $532 \mathrm{~nm}$ of supernatants against the blank. By plotting the standards absorbances against their respective concentrations a standard curve was obtained, and the MDA concentrations were extrapolated by using the formula:

Amount of sample MDA /L of serum

Results were expressed as MDA $(\mu \mathrm{mol}) / \mathrm{L}$ of serum.

\section{Statistical analysis}

One - way analysis of variance (ANOVA) was utilized to analysis the data by utilizing SPSS 23-windows (SPSS Inc., Chicago, IL, USA). Range, mean, and standard deviation were used to show the data. The Kolmogorov Smirnov test was applied to determine the normal distribution of the present data.

\section{Results}

The biochemical and clinical characteristics of participating groups are shown in (Table 1). The results show a significant rise in the levels of glycated hemoglobin for diabetic patient's groups compared to the health group. While the microalbuminuria, was showed a significant increase in diabetic patients with nephropathy compared to diabetic patients without nephropathy.

Table 2 shows the significant elevation in the total antioxidant species and malondialdehyde concentrations of diabetic groups with and without nephropathy compared with healthy group subjects. Elevation ROS concentration refers to oxidative stress incidence in tissues of 
diabetic patient. On the other hand, total antioxidant concentrations and catalase activity was decreased in sera diabetic patient groups with and without nephropathy compared with healthy group subjects. The decrement of antioxidant levels signifies to the inclination of oxidative stress in diabetic patient with and without nephropathy. Selenium-dependent glutathione peroxidase activity, nonselenium dependent glutathione peroxidase activity and total glutathione peroxidase activity were showed a significant decrement in sera of diabetic groups with and without nephropathy compared with healthy group subjects.

Table 1. The biochemical and clinical characteristics of participating groups.

\begin{tabular}{llll}
\hline \multicolumn{1}{c}{ Parameter } & Healthy subjects & Diabetic Patients & $\begin{array}{c}\text { Diabetic Patients with } \\
\text { Nephropathy }\end{array}$ \\
\hline Number & 60 & 60 & 60 \\
Age $(\mathrm{yrs})$ & $45.5 \pm 7.5$ & $46.5 \pm 6.1$ & $45 \pm 7.0$ \\
BMI $\left(\mathrm{kg} / \mathrm{m}^{2}\right)$ & $22.6 \pm 1.2$ & $22.2 \pm 1.5 \mathrm{NS}$ & $21.5 \pm 1.6 \mathrm{NS}$ \\
HbA1c & $5.1 \pm 0.42$ & $8.1 \pm 1.4^{*}$ & $7.9 \pm 2.1^{*}$ \\
Microalbuminuria $(\mathrm{mg} / \mathrm{L})$ & $10.3 \pm 3.3$ & $11.71 \pm 5.53 \mathrm{NS}$ & $101.33 \pm 35.55^{*}$ \\
\hline
\end{tabular}

$N S$ : non-significance versus healthy donors.

*: significance versus healthy donors.

Table 2. The clinical parameters measurements in the current study.

\begin{tabular}{|c|c|c|c|}
\hline & G1 & G2 & G3 \\
\hline $\begin{array}{l}\text { Se-GPx } \\
(U / L)\end{array}$ & $551.8^{\vee} \pm 243.3^{\prime}$ & $419.2^{9} \pm 277.4^{7 *}$ & $316.6^{\vee} \pm 212.81^{*}, \$$ \\
\hline $\begin{array}{l}\text { Non Se-GPx } \\
(U / L)\end{array}$ & $217.1^{\circ} \pm 86.5^{7}$ & 168.0 r & $134.9^{9} \pm 69.7 r^{*}$ \\
\hline $\begin{array}{l}\text { Total GPx } \\
(U / L)\end{array}$ & $769.0^{\prime} \pm 242.31$ & $554.2^{\wedge} \pm 279.77^{*}$ & $484.7^{\prime} \pm 232.0^{\wedge} *$ \\
\hline $\begin{array}{l}\text { Catalase } \\
(k a t U / \mathrm{ml})\end{array}$ & $0.6^{\vee} \pm 0.21$ & $0.5^{\circ} \pm 0.2^{9^{*}}$ & $0.5^{\prime} \pm 0.2^{\wedge} *$ \\
\hline $\begin{array}{l}\text { Total antioxidant } \\
(\mu \mathrm{mol} / 1)\end{array}$ & $956.6^{\circ} \pm 325.3^{\prime}$ & $822.1^{\vee} \pm 396.8^{\wedge *}$ & \$ $630.9 \pm 485.9)^{*}$ \\
\hline $\begin{array}{l}\text { Total oxidant } \\
(\mu \mathrm{mol} / 1)\end{array}$ & $7.9^{1} \pm 5.9 \varepsilon$ & $11.0^{\circ} \pm 7.47^{*}$ & $11.7 \longleftarrow 6.77 *$ \\
\hline $\begin{array}{l}\text { Malondialdehyde } \\
(\mu \mathrm{mol} / 1)\end{array}$ & $3.5^{\wedge} \pm 1.9^{\curlyvee}$ & $5.0^{9} \pm 1.8^{\circ *}$ & $6.33^{\prime} \pm 1.9 r^{*}, \$$ \\
\hline
\end{tabular}

*: significance versus healthy donors at the level of (0.05).

$\$$ : significance versus diabetic groups without nephropathy at the level of (0.05).

\section{Discussion}

Diabetes type 2 is associated with many complications that lead to damage of various organs of the human body (19). Diabetic nephropathy has been described as positive proteinuria, $0.5 \mathrm{~g} / 24 \mathrm{~h}$ of microalbuminuria (20). A clinical study was documented that $40 \%$ of patients with diabetes develop into diabetic nephropathy (21).
Previous studies were clarified the linkage of oxidative stress with diabetes pathogenesis. In diabetes condition, the free radicals' overproduction initiate through the process of glucose oxidation. This abnormal elevation of free radicals' concentration is accompanied with a clear decline of antioxidant defense mechanisms. This conditions of oxidative stress 
lead to an accumulation of damage to cellular organelles, increment lipid peroxidation, development insulin resistance (22). The kidney is especially exposed to structural and functional damage that caused oxidative stress, which accompany to hyperglycemia. In the healthy state, fibroblasts, glomerulus, and renal tubules cells provide NADPH oxidase and contribute to generation of reactive oxygen species in small quantities. In chronic hyperglycemia, ROS generation can be increased by dysfunctional renal cells that will cause injuring the renal tissues. Chronic hyperglycemia in the renal milieu stimulates alternative pathways is called polyol pathway that cause tissue damage. Also, mitochondrial reactive oxygen species overproduction contributes with polyol pathway to form intracellular glycation end products (AGEs) (23). Our study is in-line with those of Duncan, who notify elevated ROS levels in T2DM with and without nephropathy (24).

Table 2 was shown that selenium-dependent glutathione peroxidase activity, non-selenium dependent glutathione peroxidase activity and total glutathione peroxidase activity were showed a significant decrement in sera of diabetic groups with and without nephropathy compared with healthy group subjects. The noticeable role of diabetes and the resulting development of metabolic abnormalities, which cause increment ROS concentration in mitochondria-rich beta cells will affect GPX activity negatively (25). Hyperglycemia develops superoxide production excessively, where $\mathrm{O}_{2}{ }^{--}$and $\mathrm{H}_{2} \mathrm{O}_{2}$ formed from elevated superoxide dismutase activity. The reactive oxygen species such as $\mathrm{O}_{2}{ }^{--}$and $\mathrm{H}_{2} \mathrm{O}_{2}$ act to inhibit Gpx activity (6). The decrease in GSH mainly affects the enzyme activity and the detoxification rate of peroxides, where GSH acts as a substrate for GPX (26). Elevation the levels of the main glutathione peroxidase substrate organic hydroperoxides acts to promote diabetes complications and change cell membrane (27). Previous researches reported a negative correlation between lipid peroxidation and glutathione peroxidase activity in diabetic and diabetic nephropathy (28). On the other hand, several studies have reported a decrease in Selenium concentration in the blood of diabetic patients (29). A positive correlation was documented between glutathione peroxidase activity and selenium concentration (30). All the GPX subunits contain selenium atom linked to the active side. It is believed that selenium deficiency leads to a rise of oxidative stress and development a diabetic nephropathy (31). Also, previous study has reported a negative association between microalbuminuria and plasma concentrations of $\mathrm{Se}$ and GPx in diabetic patients (32). More ever, in another study, Se supplementation was effective in increment cellular GPx activity in patients with different stages of chronic kidney disease (33). The current results are compatible with the findings of the study of Sedighi et al. that reported a decrement of GPx activity in T2DM with and without nephropathy (32).

The current study indicates that the decrease catalase activity in plasma of diabetic patients (table 2). Always, the decrement of catalase activity is accompanied with the weakening of the hydrogen peroxide decomposition efficiency $(34,35)$. Low catalase activity causes cell death and an increase in the production of highly toxic hydroxyl radicals when associated with redox-active metal ions. Kidney fatigue continuously as a result of diabetic complications greatly affects catalase activity and prevents its continued action in combating the increase in hydrogen peroxide (36). Catalase shares with glutathione peroxidase in the ability to break down hydrogen peroxide, but catalase is abundant in peroxisomes and is lacking in mitochondria, so glutathione peroxidase complements the role of catalase in dealing with the detoxification of hydrogen peroxide and its conversion to water (37).

Decreasing antioxidants levels in the two groups of diabetics as shown in table (2) indicates a clear imbalance in the defense system. The presence of diabetes causes ROS excess, which in turn affect the defenses of antioxidant mechanisms that work collectively to maintain the normal range of oxidant/ antioxidant balance (38). The result (table 2) shows elevation total oxidant concentration and 
decrement total antioxidant concentration in diabetic patient with and without nephropathy. Maintaining an equilibrium state for oxidants and antioxidants provides superior protection for all cell components and prevents cellular impairment (39). The overall antioxidant capacity may provide more appropriate biological information compared to that achieved by the assessment of individual factors, as it is concerned about the collective influence for whole antioxidants that found in plasma and body fluids (40). Our study is compatible with conclusions of Singla et al. study that report the decrement of total antioxidant levels in T2D with and without nephropathy (41).

Lipid hydroperoxide affects the cell membrane and weakens its function. In addition, the most dangerous product of reactive

\section{References}

1. Williams JE, Helsel B, Nelson B, Eke R. Exercise Considerations for Type 1 and Type 2 diabetes. ACSM's Health \& Fitness Journal. 2018;22(1):10-16.

2. Scheid DC, McCarthy LH, Lawler FH, Hamm RM, Reilly KEH. Screening for microalbuminuria to prevent nephropathy in patients with diabetes: A systematic review of the evidence. J Fam Pract. 2001;50(8):661-8.

3. Najafian B, Fogo AB, Lusco MA, Alpers CE. AJKD Atlas of Renal Pathology: Diabetic Nephropathy. Am J Kidney Dis. 2015;66(5):e37-8.

4. Rani V, Deep G, Singh RK, Palle K, Yadav UCS. Oxidative stress and metabolic disorders: Pathogenesis and therapeutic strategies. Life Sci. 2016;148:183-93.

5. Lubos E, Loscalzo J, Handy DE. Glutathione peroxidase-1 in health and disease: From molecular mechanisms to therapeutic opportunities. Antioxidants Redox Signal. 2011;15(7):1957-97.

6. Karunakaran U, Park KG. A systematic review of oxidative stress and safety of antioxidants in diabetes: Focus on islets and their defense. Diabetes Metab J. 2013;37(2):106-12.

7. Forbes JM, Coughlan MT, Cooper ME. Oxidative stress as a major culprit in kidney disease in diabetes. Diabetes. 2008;57(6):1446-54. oxygen species can affect intensely the lipids is hydroxyl radical, which is considered reactive chemically and can attack biological molecules (42). Our results are compatible with the findings of Kumawat et al study that reported elevation malondialdehyde concentration in T2D with and without nephropathy (28). The increase in lipid peroxidation is also an indication of weakening in antioxidative defense mechanisms (e.g. glutathione peroxidase which detoxifies lipid hydroperoxide) (43).

\section{Acknowledgements}

We extend our sincere thanks to all Al-Fadhel Foundation researchers for providing us with the technical assistance to complete the research.

8. Sekhon LH, Gupta S, Kim Y, Agarwal A. Female Infertility and Antioxidants. Current Women`s Health Reviews. 2010;6(2).

9. Ahmadvand $\mathrm{H}$, Ghasemi Dehnoo $\mathrm{M}$, Cheraghi R, Rasoulian B, Ezatpour B, Azadpour $\mathrm{M}$, et al. Amelioration of altered serum, liver, and kidney antioxidant enzymes activities by sodium selenite in alloxan-induced diabetic rats. Reports Biochem Mol Biol. 2014;3(1):14-20.

10. Biesalski HK, Bischoff SC, Boehles HJ, Muehlhoefer A. Working group for developing the guidelines for parenteral nutrition of The German Association for Nutritional Medicine. Water, electrolytes, vitamins and trace elementsGuidelines on Parenteral Nutrition, Chapter 7. GMS German Medical Science. 2009;7.

11. Margis R, Dunand C, Teixeira FK, MargisPinheiro M. Glutathione peroxidase family - An evolutionary overview. FEBS J. 2008;275(15):3959-70.

12. Pagana KD, Pagan TJ. Manual of Diagnostic and Laboratory Tests. Elsevier. 2018.

13. Abraham EC, Huff TA, Cope ND, Wilson JB, Bransome ED, Huisman TH. Determination of the glycosylated hemoglobins (Hb A1) with a new microcolumn procedure. Suitability of the technique for assessing the clinical management of diabetes mellitus. Diabetes. 1978; 27(9):931-7 
14. Rotruck JT, Pope AL, Ganther HE, Swanson AB, Hafeman DG, Hoekstra WG. Selenium: Biochemical role as a component of glatathione peroxidase. Science. 1973;179(4073):588-90.

15. Hadwan MH. New method for assessment of serum catalase activity. Indian Journal of Science and Technology. 2016;9(4):1-5.

16. Campos C, Guzmán R, López-Fernández E, Casado Á. Evaluation of the copper (II) reduction assay using bathocuproinedisulfonic acid disodium salt for the total antioxidant capacity assessment: The CUPRAC-BCS assay. Anal Biochem. 2009;392(1):37-44.

17. Erel O. A new automated colorimetric method for measuring total oxidant status. Clin Biochem. 2005;38(12):1103-11.

18. Buege JA, Aust SD. Microsomal Lipid Peroxidation. Methods Enzymol. 1978;52:302-10.

19. Chawla A, Chawla R, Jaggi S. Microvasular and macrovascular complications in diabetes mellitus: Distinct or continuum? Indian $\mathrm{J}$ Endocrinol Metab. 2016;20(4):546-551.

20. Brugnara L, Novials A, Ortega R, De Rivas B. Clinical characteristics, complications and management of patients with type 2 diabetes with and without diabetic kidney disease (DKD): A comparison of data from a clinical database. Endocrinol Diabetes Nutr. 2018;65(1):30-38.

21. Tönnies T, Stahl-Pehe A, Baechle C, Castillo K, Yossa R, Holl RW, et al. Diabetic nephropathy and quality of life among youths with long-duration type 1 diabetes: A population-based cross-sectional study. Pediatr Diabetes. 2019;20(5):613-621.

22. Henriksen EJ. Role of Oxidative Stress in the Pathogenesis of Insulin Resistance and Type 2 Diabetes. Bioactive Food as Dietary Interventions for Diabetes. 2019.

23. Singh DK, Winocour P, Farrington K. Oxidative stress in early diabetic nephropathy: Fueling the fire. Nat Rev Endocrinol. 2011;7(3):176-84.

24. Duncan JG. Mitochondrial dysfunction in diabetic cardiomyopathy. Biochimica et Biophysica Acta (BBA) - Molecular Cell Research. 2011;1813(7):1351-1359.

25. Likidlilid A, Patchanans N, Peerapatdit T, Sriratanasathavorn C. Lipid peroxidation and antioxidant enzyme activities in erythrocytes of type 2 diabetic patients. J Med Assoc Thai. 2010;93(6):682-93.

26. Low PA. Oxidative Stress and Excitatory Neurotoxins in Neuropathy. In: Peripheral Neuropathy. 2005.

27. Kesavulu MM, Rao BK, Giri R, Vijaya J, Subramanyam G, Apparao C. Lipid peroxidation and antioxidant enzyme status in Type 2 diabetics with coronary heart disease. Diabetes Res Clin Pract. 2001;53(1):33-9

28. Kumawat M, Sharma TK, Singh I, Singh N, Ghalaut VS, Vardey SK, et al. Antioxidant enzymes and lipid peroxidation in type 2 diabetes mellitus patients with and without nephropathy. $\mathrm{N}$ Am J Med Sci. 2013;5(3):213-219.

29. Navarro-Alarcón M, López-G De La Serrana H, Pérez-Valero V, López-Martínez C. Serum and urine selenium concentrations as indicators of body status in patients with diabetes mellitus. Sci Total Environ. 1999;228(1):79-85

30. Beckett GJ, Arthur JR. Selenium and endocrine systems. J Endocrinol. 2005;184(3):455-65.

31. Calabrese V, Mancuso C, Sapienza M, Puleo $\mathrm{E}$, Calafato $\mathrm{S}$, Cornelius $\mathrm{C}$, et al. Oxidative stress and cellular stress response in diabetic nephropathy. Cell Stress Chaperones. 2007;12(4):299-306.

32. Sedighi O, Makhlough A, Shokrzadeh M, Hoorshad S. Association between plasma selenium and glutathione peroxidase levels and severity of diabetic nephropathy in patients with type two diabetes mellitus. Nephrourol Mon. 2014;6(5):e21355.

33. Reddi AS, Bollineni JS. Selenium-deficient diet induces renal oxidative stress and injury via TGF- $\beta 1$ in normal and diabetic rats. Kidney Int. 2001;59(4):1342-53.

34. Claiborne A. Catalase activity. In: Handbook Methods for Oxygen Radical Research. 2018. 35. Dave GS, Kalia K. Hyperglycemia induced oxidative stress in type- 1 and type- 2 diabetic patients with and without nephropathy. Cell Mol Biol (Noisy-le-grand). 2007;53(5):68-78.

36. Ighodaro OM, Akinloye OA. First line defence antioxidants-superoxide dismutase (SOD), catalase (CAT) and glutathione 
peroxidase (GPX): Their fundamental role in the entire antioxidant defence grid. Alexandria Journal of Medicine. 2018;54(4):287-293.

37. Bai J, Rodriguez AM, Melendez JA, Cederbaum AI. Overexpression of catalase in cytosolic or mitochondrial compartment protects HepG2 cells against oxidative injury. J Biol Chem. 1999;274(37):26217-24.

38. Bashan N, Kovsan J, Kachko I, Ovadia H, Rudich A. Positive and negative regulation of insulin signaling by reactive oxygen and nitrogen species. Physiol Rev. 2009;89(1):27-71.

39. Birben E, Sahiner UM, Sackesen C, Erzurum S, Kalayci O. Oxidative stress and antioxidant defense. World Allergy Organ J.

40. Sies H. Total antioxidant capacity: Appraisal of a concept J Nutr. 2007;137(6):1493-5.

Singla H, Goyal G, Garg C, Bhalla K. Total antioxidant status in type 2 diabetes mellitus with diabetic nephropathy. IJAM. 2019. 42. Dimayuga FO, Wang C, Clark JM, Dimayuga ER, Dimayuga VM, BruceKeller AJ. SOD1 overexpression alters ROS production and reduces neurotoxic inflammatory signaling in microglial cells. J Neuroimmunol. 2007;182(12):89-99.

43. Arthur JR. The glutathione peroxidases. Cellular and Molecular Life Sciences CMLS. 2000;57(13-14):1825-1835.
\end{abstract} 2012;5(1):9-19. 